inches. There was a small quantity of fluid in the sac of the peritonæum. 'The vena azy gos was somewhat enlarged; the spleen was of enormous size, and almost black from congestion; the right kidney was soft, pale, and flabby; the left was enlarged; the cortical portion mottled and compact; the heart and lungs healthy.

Fig. 1. will sufficiently illustrate the mode in which the blood, diverted from its usual course by so terrible an obstacle, at last reached the centre of the circulation. Of course the impediment had come on gradually, and so tine was given for the development of the collateral supplementary veins.

The symptoms during life were therefore in accordance with what we should expect from the presence of such a growth. The hæmatemesis, I should suppose, may be attributed to obstruction in the branches of the portal system. The gorged spleen may be referred to the same cause.

Kensal-town, 1852.

\section{REPORT OF A}

\section{CA E OF CATALEPSY,} ILLUSTRATING SOMB

\section{NEW PRINCIPLES OF TREATMENT IN CON- VULSIVE AND SPASMODIC DISEASES.}

\section{By C. B. RADCLIFFE, M.D., L.R.C.P.}

WrLliaM $B$ - aged twelve, residing with his parents at Shepherd's-bush, Bayswater, was seized on the 1st of February last with a painless rigidity of his fore-arms and hands, which lasted without any interruption from tea-time, when it first made its appearance, until bed-time. Similar symptoms also recurred daily for many days, sometimes beginning early in the morning and lasting throughout the day, at other times merely showing themselves for a few minutes, while the patient was preparing for bed; and so they continued to do until the $28 \mathrm{th}$, at which time they extended to the feet and legs, and in a less degree to the upper arms, thighs, and trunk, consciousness being now completely suspended, which was not the case previously. These general symptoms, which were evidently those of catalepsy, alternated with the more partial symptoms, occurring several times in a single day, and recurring throughout the whole of the next week, at the expiration of which period the case was brought to me.

During all these fits, partial or general, the rigid parts were cold,--so cold as to cause some of the bystanders to say they were dead. Cold, also, had evidently much to do in the matter as an efficient cause. In the earlier stages of the affection, playing out of doors (the weather at the time being very severe) invariably sent the patient into the house crying, with his hands and forearms immoveable; and the exposure caused by undressing in a cold bed-room at night gave rise to the same symptoms. On the morning on which he was brought to me, also, the cold had acted in the same manner, and it was not until he had been some time seated in the warm room that the stiffening relaxed. I had thus an opportunity of satisfying myself that the parts which had lost their pliability were in reality cold, and that the pulse in them was almost extinguished, and the sensibility all but departed. I had the opportunity of satisfying myself also that this depressed con dition extended more or less to the system generally, and that all the mental and bodily functions were as far as possible removed from anything akin to excitement.

The other facts in connexion with this case all denoted the want of real power. He was anything but precocious,-not walking for two years, and not talking for a year later, and now speaking with hesitation,-very slow in apprehension, feeble in memory, and, though twelve years of age, as irritable, uncertain, and fretful as a child. His head is large; his eyes staring, and their pupils dilated and sluggish; his complexion sallow and venous; his hand cold and clammy; his pulse slow (70) and feeble; his body prominent and hard; his appetite voracious. The body, moreover, is covered with boils; and it is further to be observed that the symptoms first showed them selves after the inherent feebleness had been further depressed by a severe cold. Both parents appear to be healthy, but a cousin of the mother suffered from fits of a similar character, and lost her life in one of them, by falling from a foot-bridge into a brook.

Acting upon received views, that increased irritation in the chief nervous centres had to do with the muscular rigidity, Mr. Roy, of Brook-green, had tried the usual course of leeches behind the ears, blisters to the nape of the neck, low diet, mercurials, hot mustard fomentations to the feet, and so on; but finding the symptoms becoming more general and confirmed, he sent the case to me.

The treatment I pursued was in accordance with the opinion $I$ have set forth in these matters, * that muscular contraction, whether normal or abnormal, is itself the sign and consequence, not of increased, but of diminished innervation and vitalization. I therefore recommended that the patient should be kept still, and as warm and comfortable as possible; that animal food and good table-beer should be given him freely; that he should be undressed before the fire, and carried to bed wrapped in warm flannels, having been first for some time immersed in a hot bath; and that he should take every few hours a sinall teasnoonful of spirits of turpentine, with ten drops of aromatic spirits of ammonia, mixed up with a part of the yolk of an egg, in a little ginger wine.

A fortnight after this first interview, I saw the patient again, and found that the dranght had occasioned a little irritation in the bladder, but so little that there was no necessity to discontimue the remedy. On the other hand, it had put a stop to a troublesome and old-established habit of micturating in bed. As to the rest, there was a material improvement in every respect, the countenance being brighter and more energetic, and there having been no cataleptio rigidity from the day the stimulant and nutritive plan of treatment had been put in practice.

I saw the patient no more, but I learned from the mother, who called to thank me two months subsequently, that the treatment had been carried out for a month longer, that the fits had never returned, and that he was then in better health than he had ever been before.

Henrietta-street, Cavendish-square, 1852.

ON SOME OF THE MORE IMPORTANT POINTS IN THE PHYSIOLOGY, PATHOLOGY, AND PRACTICE OF MIDWIEERY.

\author{
Bч J. POWER, M.D., \&c. \\ (Continued from $p .80$.)
}

Abnormal Parturition (continued).-2. Where the abnormal condition depends on morbid or unnatural actions of the organs concerned.- The more leading feature of the author's treatise on midwifery was an attempt to show that the pains so generally accompanying labour were not essential to the process, but admitted of being lessened or removed, with the effect of inducing more vigorous and propitious uterine action, views suggested and confirmed by several years of previous observation and experience, and which, however they might have been questioned at the time, are now virtually admitted in the science of midwifery, but with little or no ackvowledgment of the source from which they have been derived. In a recent work, t the only allusion made to these views is where its author, when treating of rheumatism and inflammation of the womb in labour-both rare if not suppositious cases, says :- "We presume it is to these cases that Dr. Power alludes when he says "the improper action will be removed almost instantly, and as it were by a miracle, so that a case which has been protracted for the greater part of a week, under the most intense suffering, and without the least progress, has been happily terminated in fifteen or twenty minutes from the first commencement of the friction."

Whoever may think proper to consult the original work of the author cannot fail to be sensible of the injustice and inaccuracy of the above dictum, which can only have been suggested by a hasty or partial reading, or an imperfect comprehension of the views therein inculcated.

A large majority of the morbid states comprised in the present consideration were advanced, in the first instance, as the results of that principle then known in the doctrines of medical science under the term "metastasis," the parturient energy being assumed to be transferred, in consequence of sympathy or association, from the uterus to other, and sometimes very distant and distinct parts. This principle may now be considered as virtually established, although it has more recently been explained by referring the transference in question to "reflex action," or, in other words, by contemplating it under new name.

The doctrine of reflex or diastaltic action (previously alluded to (The Lancet, p. 79) has doubtless conferred lasting honour on Dr. Marshall Hall, and contributed essentially to a better * Comments on Convulsive Diseases. 1851. † Rigby's System of Midwifery, p. 242. 